\title{
DEVELOPING TERTIARY LEVEL CLIL LEARNERS' INTERCULTURAL AWARENESS WITH A SELF-PRODUCED COURSEBOOK INTEGRATING CONTENT AND LANGUAGE
}

\author{
Wen-hsien Yang \\ National Kaohsiung University of Hospitality and Tourism, Taiwan \\ E-Mail: yangwenhsien@mail.nkuht.edu.tw
}

\begin{abstract}
Integrating content and language at tertiary level has recently become very popular in Asian contexts. Extensive studies have also been done, evidencing that CLIL (Content and Language Integrated Learning) can be beneficial for improving learners' linguistic outcomes and content achievements. However, cultural awareness, as one core dimension of the 4Cs (communication, content, cognition, and culture) conceptual framework is less addressed in the literature. Often it is assumed that CLIL education can also naturally increase learners' cross-cultural competence, but hard evidence on the increment of this competence is still lacking in the CLIL literature. Thus, to bridge this gap, the present study used a mixed research method to investigate to what extent a self-produced CLIL culture coursebook can help university students enhance their inter-cultural knowledge in a national Taiwan polytechnic university. One survey was conducted to evaluate the tailor-made CLIL materials and another was administered to measure the cultural competence after the CLIL intervention. The coursebook writers as well as the CLIL learners were also interviewed in the study. The findings showed that the contextualised design met its set educational aims and targets, and the users made significant improvement in their cultural competence. Also, the interviewees showed a high degree of satisfaction with the coursebook and the approach, although the book authors held divided opinions on some issues. Implications and suggestions are provided.
\end{abstract}

Key words: $C L I L$, intercultural awareness, $C Q$, material evaluation, tertiary level

\section{INTRODUCTION}

In the $21^{\text {st }}$ century, in such a globalised society, there should be new missions, aims, and goals of higher education (HE). The new mission of HE institutes is to equip graduates with professional knowledge and proficient language skills that can be utilised across borders since national borders are becoming increasingly blurred. In addition, intercultural competence contributes to successful mobility across contexts. While developing cultural understanding and competence, transformative pedagogies, global citizenship, student voice or identity investment should be initiated as core elements (Cummings, 2004). Cultural competence is defined as "the ability to participate ethically and effectively in personal and professional intercultural settings. It requires being aware of one's own cultural values and world view and their implications for making respectful, reflective and reasoned choices, including the capacity to imagine and collaborate across cultural boundaries" (Sherwood,

Submitted October $13^{\text {th }}, 2019$, accepted for publication November $18^{\text {th }}, 2019$

(C) 2019 by University of Niš, Serbia | Creative Commons License: CC BY-NC-ND 
2019). At present, the capacity of demonstrating one's cross-cultural competence has drawn the attention of both the business sector and HE institutions as they respectively dispatch employees overseas and select students to join international exchange programmes. The cultural intelligence or quotient (CQ) scale has been developed to serve as a quantitative measure to provide a unified strategy and skill set for how to relate, work, live or study across cultural differences at home and abroad (CIC, 2019).

Recently, the CLIL (Content and Language Integrated Learning) approach with its dual-focused aim has been rapidly emerging in Asian EFL contexts (Yang, 2015). In CLIL education, Coyle's (1999) 4Cs framework is considered as effectively portraying the four dimensions of the CLIL conceptual base; thus, it is often used to represent the four facets of developing CLIL pedagogies. Coyle's framework centres on the interplay of communication skills, content knowledge, cognition learning and cultural awareness, and considers different levels of integration: "learning (content and cognition), language learning (communication and cultures) and intercultural experiences" (Coyle, 2007: 550). Culture plays an indispensable role in teaching the target language in CLIL pedagogy as it represents the patterns, customs and ways of life of the speakers of that specific language (Brown, 1980). However, since the emergence of CLIL in the 1990s in Europe, extensive research, including conceptual, empirical and experimental studies have been done to examine the first three Cs, that is, language outcomes, content achievements and cognitive thinking; however, unfortunately, how the CLIL approach has effectively facilitated and to what extent CLIL learners have precisely developed their intercultural awareness and knowledge have been investigated to a lesser extent, despite the fact that they are fundamental to CLIL (Coyle, 2008). In other words, there is still a severe lack of research on culture's role in CLIL education, and this area has yet to attain importance (Coyle, 2007). Hence, the present research attempts to study this under-researched topic to reveal how learners' cross-cultural knowledge can be enhanced with a tailor-made coursebook and explicit instruction under the CLIL approach.

\section{LITERATURE REVIEW}

\subsection{Cultural intelligence (CQ) and developing cultural competence}

The CQ scale (CQS) was developed to assess and improve effectiveness in culturally diverse situations (Ang \& Van Dyne, 2008). Cultural intelligence refers to "the ability to relate and work effectively with people from different cultural backgrounds and it goes beyond existing notions of cultural sensitivity and awareness" (CIC, 2019). It can be further divided into global CQ which enables people to live, work, study and communicate effectively with others in international contexts, and domestic CQ which helps people do the same things with those from other cultural backgrounds in their home country. People with cultural intelligence know how to strategically use cultural differences to effectively adapt to multicultural challenges and then function and produce more innovative solutions (Earley \& Peterson, 2004). It is predicted that universities with highly culturally intelligent students can better accomplish their educational missions in today's multicultural, globalized and competitive HE environment (CIC, 2019).

Like the four pillars of the CLIL conceptual framework, CQ is also composed of four domains. However, unlike the 4Cs in CLIL pedagogy, which are interwoven with each other, the four dimensions in CQ move in a linear cycle. CQ starts from an intrinsic drive to feel interested, motivated and confident while functioning in a multicultural situation 
(Motivational CQ). Then, the drive pushes a person to understand and obtain knowledge of differences or similarities between cultures (Cognitive CQ). Next, s/he would employ certain strategies to keep alert to differences or similarities and check after intercultural interactions (Meta-cognitive CQ). Finally, s/he would take actions to behave appropriately and flexibly in response to a broad multicultural repertoire and encounters (Behavioural CQ) (CIC, 2019). The procedure of developing cultural intelligence should be treated as a refining cycle without a definite end.

Since its establishment, CQS has been broadly used across various settings and situations. Research on the efficacy of its use is, thus, extensively documented. There have been conceptual research, empirical research, practical papers and case studies on CQS application and benefits conducted in both business organisations and higher education institutes. In the present research, we review relevant studies in the HE sector. First of all, Varela and Gatlin-Watts (2014) employed a pre- and a post-test to examine the effect of business students studying abroad on the metacognitive, cognitive, motivational, and behavioural dimensions of multicultural competence, and found that studying abroad made the students act differently in the CQ dimensions. The students demonstrated development of the cognitive-based components of the competence, and the study concluded that studying abroad can increase participants' motivational and behavioural cultural intelligence. Besides, Chao, Takeuchi, and Farh (2017) also commented that university students' implicit culture beliefs affected their intercultural rejection sensitivity, "which impacted the cross-cultural adjustment of sojourning students and their subsequent CQ" (p. 257). They, especially, discovered that cross-cultural adjustment experiences of joining an international exchange programme, in particular in the social dimension, are an important factor in influencing CQ performance. Similarly, Holtbrugge and Engelhard's (2015) study confirmed that those students who have studied abroad would exhibit positive relationships between cultural boundary spanning and the four CQ capabilities.

Regarding offering cultural instruction to prepare students (including undergraduates and postgraduates) to function effectively in multicultural encounters, a number of empirical studies have evidenced that the experimental group taught with cross-cultural knowledge in a course or in a simulation mode showed an overall increased CQ performance compared with the control group without the same provision (e.g. Buchtel, 2014; Bücker \& Korzilius, 2015; Eisenberg, Lee, Brück, Brenner, Claes, Mironski, \& Bell, 2013; Engle \& Crowne, 2014; Erez, Lisak, Harush, Glikson, Nouri, \& Shokef, 2013).

However, the aforementioned studies also agreed that not all of the four dimensions of CQ can increase equally, and sometimes the instruction did not affect cross-cultural communication effectiveness (Bücker \& Korzilius, 2015). Fisher's (2011) study even revealed that after CQ training, students' cognitive and meta-cognitive CQ decreased due to the fact that their awareness of the challenges of cross-cultural interactions was enhanced following the intervention. Besides, Buchtel (2014) cautioned that explicit instruction on CQ may have negative results for those with lower CQ grades. These students "increased their endorsement of stereotypes that were not endorsed by cultural psychology research" (p. 40). Although CQS has been used and CQ intervention has been conducted comprehensively, relatively few investigations have been done in Asian contexts. 


\subsection{Designing and evaluating CLIL materials to raise cultural awareness}

Recently, the CLIL approach has grown rapidly and gained popularity in Asian countries, but one common doubt or concern of possible extensive implementations in the future is that there is a severe lack of tailor-made teaching materials for CLIL courses (Coyle, Hood, \& Marsh, 2010; Yang, 2018). As a result, CLIL practitioners may rely heavily on centralised or ready-made materials (Yang, 2020). Currently, CLIL materials are mostly written based on EFL principles to cater to a large international market (Banegas, 2014) and thus customised adaptation and connection to local cultures are rarely detected (Bell \& Gower, 2011; Tomlinson, 2012). Furthermore, these TESOL-based CLIL materials tend to overlook the balance of content and language designs (Coyle, Hood, \& Marsh, 2010). Another critical issue of producing CLIL materials is the obvious imbalance in the weighting of content and language teaching, depending on who, language teachers or content specialists, write the materials. Studies have found that content learning tends to outweigh language design if the materials are produced by language teachers (Banegas, 2015: Nikula, 2012), although sometimes language teachers overstress the four language skills and grammar compared with the content knowledge in the books (Baecher, Farnsworth, \& Ediger, 2014). To the best of our knowledge, CLIL coursebooks or materials are seldom produced by content specialists. In other words, CLIL material development is still in its infancy (Floimayr, 2010).

Due to the lack of commonly-recognised systems for judging the quality of CLIL materials, sometimes the rules of evaluating EFL books would be used as most of the current materials are often designed in a language-based weak CLIL form. However, these criteria may not be appropriate for the conceptual framework of CLIL pedagogy (Banegas, 2014; Yang, 2018). Several CLIL researchers have attempted to establish the principles of evaluating quality CLIL materials such as Ball, Kelly, and Clegg (2015), Mehisto (2012), and Yang (2018), who used Mehisto's standards to appraise his self-produced CLIL textbook. These established principles are comprehensively holistic, but one concern of any standardised evaluation criteria is the lack of connection with and relevance to contextualisation, which is a key factor in successful CLIL implementations (Coyle, 2007).

Substantial CLIL studies have explored learners' language outcomes and content achievements under the CLIL approach, but only a limited number of studies have addressed the learners' development of cultural awareness or competence. For instance, Méndez García (2012) conducted a case study on CLIL primary and secondary school teachers' and students' perceptions in Andalusia, examining if learners are equipped with the necessary competences to cope efficiently with otherness. Their findings showed that CLIL has the potential to develop students' crucial intercultural attitudes and critical cultural awareness. Similarly, Rodríguez and Puyal (2012) in Spain had CLIL learners read literary works in English to confirm that their intercultural competence could be fostered with the provision of literary texts in CLIL classrooms. In a Greek primary school, a CLIL programme was designed to help Albanian immigrants to think in the target language and become aware of Greek cultures (Papadopoulos \& Griva, 2014). In Portugal, Logioio (2010) used the storytelling technique to raise young CLIL learners' cultural awareness of otherness about Asian cultures. Most of these investigations are self-reported and perception-based. One rare case of using a cultural awareness checklist to measure 38 CLIL Egyptian university students' CQ change is Diab, Abdel-Haq and Aly's (2018) empirical study. They administered two tests before and after a CLIL course and discovered a significant increment of the CQ performance among the participants. 
Although it is suggested that the potential for the intercultural learning process is rather high and can be fulfilled successfully in CLIL classrooms (Sudhoff, 2010) and "the importance of elements such as cultural identity, intercultural communication, intercultural awareness is great in the field of research in the CLIL area" (Oprescu, 2015), more hard evidence of how CLIL learners' cultural competence has precisely progressed as a result of explicit interventions is needed, particularly at the EFL tertiary level in Asian contexts. Thus, our study aims to bridge this gap.

To be specific, we aimed to answer the following questions:

1. How do CLIL learners evaluate a self-produced CLIL culture textbook?

2. Are there any significant differences in CLIL learners' CQ performance before and after the explicit instruction?

3. What are the learners' and material developers' perceptions of the self-produced textbook and the explicit instruction of CQ?

\section{RESEARCH METHOD}

We designed a mixed research method (QUAN + QUAL) for the present study. To answer research question 1 , we produced a localised coursebook embedded with various cultural issues, in particular corresponding to the global hospitality and tourism cultures, as these two domains are what the researched university is known for. The 14-unit book was designed based on a language-based soft CLIL approach wherein communicative skills in the target language are highly emphasised along with essential cultural knowledge about the global hospitality and tourism sectors. The book is the result of a collaboration of a group of eight ESP teachers in an Applied English Department, including native English-speakers (NS) and non-native speakers (NNS), and took 18 months to complete. The book, titled 'Connections: Diversity and Culture', was formally published in 2019 and is available for purchase (see https://www.tunghua.com.tw/portal_b9_page.php?button_ num=b9\&cnt_id=7863).

The coursebook intends to be taught to second-year students in a national polytechnic university who are planning to go overseas for one-year internship in their third year of study. They intend to stay overseas to work or study in hospitality and tourism businesses or education institutes so as to develop the intercultural-awareness that is expected to be mandatory for them to survive successfully in an unknown context. This self-produced coursebook was first trialled in the classroom in the spring term of 2019. The instructor is a non-native English speaking ESP and CLIL practitioner with more than 10 years' experience, and has studied the two areas extensively. In total, 33 English majors with average English proficiency ranging between CEFR B1 and B2 levels took this 18-week long course, of whom 18 stayed in Taiwan while 15 went overseas for their one-year placement. Of the 33 students, 24 were female and 9 were male, while 31 were from Taiwan and 2 were international students from Malaysia. In the last week, the learners were asked to complete two online surveys. The first required them to judge to what extent the book reaches its aims and targets as a cultural textbook. The survey was adopted from Farzaneha, Kohandanib, and Nejadansaric's (2014) 5-point Likert scale questionnaire which focuses on evaluating a textbook from the perspectives of social-cultural contexts, including five main categories comprised of 16 questions, that is, intercultural knowledge and understanding, cultural awareness, cultural representation, aims and achievement, and teachability. The Cronbach's alpha reached .936 in this survey. 
To answer research question 2, we administered the second survey in the first week and the $18^{\text {th }}$ week respectively as the pre- and post-tests. A total of 41 English majors completed the survey, including those who took the course (33) and those who did not (8). This on-line survey was developed from Ang and Van Dyne's (2008) cultural quotient survey (CQS) which has been used extensively in the business sector to evaluate if an employee who will be dispatched overseas is equipped with sufficient intercultural competence to work and live abroad successfully. Universities also administer it to partially assess if students who will join overseas exchange study programmes are qualified. In addition to the background information, the survey consists of 37 questions, calculating takers' scores in four dimensions, that is, motivational, cognitive, meta-cognitive and behavioural CQ performance (Bucker et al., 2015). The Cronbach's alpha of the CQ test reached .945 in this survey. SPSS was used to treat the data collected in both surveys. In addition to the descriptive analysis, $t$ test and one-way ANOVA were run to determine if significant differences existed across the variables.

Finally, we conducted interviews with the coursebook writers and the learners in order to obtain deeper understanding of how the writers designed the culture coursebook and how the students perceived the usefulness of the CLIL book and the instruction. Totally, eight learners and four teachers (2 English speakers and 2 local teachers) were invited to join the semi-structured interviews. The interviewer, also one of the coursebook designers and the course instructor, used the interviewees' mother tongues (i.e. Mandarin Chinese or English) for easy and genuine communication, and each interview lasted for about one hour. All the interviews were transcribed into English with the help of one research assistant and were verified by the researcher. The transcripts were processed by Weft QDA, a software package developed by Fenton (2004) which makes it easy to code and analyse qualitative textual data such as interview transcripts, field notes or documents. To avoid possible reservation or bias from the student interviewees, their interviews were conducted after their course grades were submitted, and thus there was no possibility of change to their grades as a result of the interview. The student interviewees were clearly guaranteed that no risk would occur even though the interviewer was the researcher and the course instructor. Trustworthiness was built to maintain the reliability of the interview data. Besides, their responses were also cross-referenced with the quantitative data to ensure the validity. The study collected much useful information; however, due to the limitation of space, we merely present some interesting findings and significant results.

\section{RESULTS AND DISCUSSION}

\subsection{CLIL learners evaluating a self-produced culture CLIL coursebook}

There are five categories asking the students to evaluate the self-produced CLIL culture coursebook from a cultural perspective. Tables 1,2, 3 and 4 show the results of the level to which the design meets the set criteria in the five categories. In general, the respondents showed an intermediate to high agreement with each statement, with an average mean of $\mathrm{M}=4.01$, which is much higher than Farzaneha, Kohandanib, and Nejadansaric's (2014) evaluation of an EFL book published by an international publisher and intended for international sale (their average mean: 2.56 across 5 categories).

In the first category, item 2 received less agreement than the other two items, although $65.6 \%$ ( 4 and 5 on the Likert scale) ${ }^{1}$ of the respondents gave high endorsement. The writing team was mainly composed of local Taiwanese teachers and native English speakers from 
the United Kingdom and the United States, which might inevitably make Anglophone cultures dominant or centred in the coursebook. Thus, information or images of the content may be presented from a certain group of norms' views, which could be stereotypical in such a globalised society. Other than that, the respondents demonstrated very high agreement with items 1 and $3(81 \%, 78 \%)$. Their responses mirror the fact that the self-designed coursebook was written from a language-based soft CLIL perspective which placed more stress on communication skills across cultures.

Table 1 Intercultural knowledge and understanding

\begin{tabular}{|c|c|c|}
\hline Item & M & SD \\
\hline 1. The social and cultural contexts in the textbooks are understandable. & 4.28 & .77 \\
\hline $\begin{array}{l}\text { 2. The content of the textbooks is free from stereotypical images and } \\
\text { information. }\end{array}$ & 3.81 & .69 \\
\hline $\begin{array}{l}\text { 3. Cross-cultural perspectives in communication and developing real } \\
\text { intercultural communication are emphasized. }\end{array}$ & 4.12 & .75 \\
\hline
\end{tabular}

Similarly, in the second category of cultural awareness, the respondents also expressed high agreement across the three items, indicating that the self-produced material is able to raise learners' sensitivity to cultural differences. However, the agreement percentage of item $6(66 \%)$ corresponds to the results of item 3, implying that writers' values, beliefs and attitudes towards cultures may be implicitly projected in the design, and they can be subtly detected by the users who do not share the same cultures as the authors.

Table 2 Cultural awareness

\begin{tabular}{|l|c|c|}
\hline Item & M & SD \\
\hline $\begin{array}{l}\text { 4. } \\
\text { The cultural content of the textbook increases sensitivity to cultural } \\
\text { diversity }\end{array}$ & $\mathbf{4 . 1 2}$ & .79 \\
\hline $\begin{array}{l}\text { 5. } \\
\text { the cultural content of the textbook promotes flexibility and } \\
\text { tolerance of }\end{array}$ & $\mathbf{4 . 1 2}$ & .75 \\
\hline $\begin{array}{l}\text { The cultural content of the textbook does not assign values to } \\
\text { cultural differences. }\end{array}$ & 3.84 & .88 \\
\hline
\end{tabular}

Compared to the other categories, the class of culture representation received the lowest agreement from the learners, with an average of $75 \%$, the highest $87.6 \%$ for item 7 and the lowest $65.7 \%$ for item 8 . The accuracy of the content is not necessarily equal to the correctness of culture representation; thus, even though a great majority of the users regarded the coursebook as having accurate content, the respondents also seemed to believe that Anglophone culture has a stronger voice than others in the materials. Stereotypical or biased views towards non-Anglophone cultures may come from the authors' unfamiliarity with and lack of exposure to them. 
Table 3 Culture representation

\begin{tabular}{|l|l|l|}
\hline Item & M & SD \\
\hline 7. $\quad$ The textbook offers cultural content as accurately as possible. & $\mathbf{4 . 0 6}$ & .56 \\
\hline $\begin{array}{l}\text { 8. } \\
\text { The textbook represents cultural content without stereotypes or an } \\
\text { essentialist perspective. }\end{array}$ & 3.81 & .78 \\
\hline $\begin{array}{l}\text { The book expresses positive views of ethnic origins, occupations, } \\
\text { age groups, social } \\
\text { groups and disability. }\end{array}$ & 3.84 & .67 \\
\hline 10. The cultural information is relevant and interesting. & 3.96 & .64 \\
\hline 11. Cultural content is usually presented in a validating context. & 3.87 & .79 \\
\hline
\end{tabular}

Tables 4 reveals to what degree the learners agreed with the categories of aims, achievement and teachability of the self-produced coursebook. This category gains the highest agreement, with an average of $80.6 \%$, the highest $93.8 \%$ for item 14 and the lowest $59.4 \%$ for item 15. A great majority of the users believed that the self-designed culture CLIL coursebook achieved the set aims and objectives, and the culture content was successfully delivered to the learners, which evidences that the book reached the aim and targets of the design. In addition, the CLIL instructor's teaching performance was believed to be natural, confident and well-prepared without much reservation or hesitancy regarding the teaching content, and the learners perceived that they were treated equally in the learning environment without feeling rejected or isolated due to their cultural backgrounds or personal beliefs about cultures. In short, the respondents showed an affirmatively high agreement with nearly all items. Hence, according to the learners' evaluation report, our language-based CLIL book obtains face validity of being able to raise users' cultural awareness, convey intercultural knowledge and understanding, and display cultural representation.

Table 4 Aims, achievement and teachability

\begin{tabular}{|l|c|c|}
\hline Item & $\mathrm{M}$ & $\mathrm{SD}$ \\
\hline $\begin{array}{l}\text { 12. The aims and objectives of including cultural content in the textbook } \\
\text { have been presented. }\end{array}$ & $\mathbf{4 . 0 3}$ & .64 \\
\hline $\begin{array}{l}\text { 13. The aims and objectives of including cultural content in the textbook } \\
\text { have been achieved. }\end{array}$ & $\mathbf{4 . 0 6}$ & .61 \\
\hline $\begin{array}{l}\text { 14. The teachers are comfortable teaching the cultural content of the } \\
\text { textbook. }\end{array}$ & $\mathbf{4 . 5 0}$ & .62 \\
\hline $\begin{array}{l}\text { 15. The cultural content of the textbook requires minimal preparation } \\
\text { and explanation by the teacher. }\end{array}$ & 3.65 & .86 \\
\hline \begin{tabular}{l} 
16. I comfortably learn cultural contexts without any sign of rejection. \\
\hline
\end{tabular} & $\mathbf{4 . 1 8}$ & .69 \\
\hline
\end{tabular}

In order to understand if different variables would affect the users' responses, $t$ test and one-way ANOVA were executed. The following tables, from 5 to 7, exhibit the statistical significance for the different variables. The factors, gender, location of future internship and English proficiency lead to some statistical differences. Generally, female students made a more significantly positive evaluation of the CLIL book than the male students did for some items $(1,4$, and 6$)$. It is assumed that female students might have more tolerant thinking or attitudes towards cultural diversity and they may benefit more from intercultural 
sensitivity raised via explicit cultural instruction than males (Altshuler, Sussman, \& Kachur, 2003). Besides, those who planned to stay in their home country agreed significantly more with the increasing sensitivity of cultural diversity the book brought to them than those who planned an overseas internship. The former learners could be intrinsically motivated to sign up for the course since it was not mandatory for them and thus they would highly appreciate if the book could sensitise them to the cultural differences as a result of the instruction.

On the contrary, those who intended to undergo an overseas internship might have projected themselves as working in foreign contexts during the class; hence, different cultures addressed in the course would positively strengthen their motivation to go overseas and increase their consensus regarding the importance of instructing cultural knowledge. Finally, those who had lower English proficiency showed higher agreement with statements 8 and 10 than the higher achievers. It is supposed that the lower English achievers might have had fewer chances of exposure to other cultures in their previous study experiences than the high achievers; thus, learning intercultural knowledge can be a new and interesting experience for them. Their responses also indicate that explicit instruction on intercultural knowledge via a CLIL approach is not only useful but essential for the learners from the less-privileged backgrounds of English learning. Although previous studies (e.g. FernándezSanjurjo, Fernández-Costales, \& Arias Blanco, 2019; Sanjurjo, Blanco, \& FernándezCostales, 2018) have evidenced that CLIL learners with less-favoured societal backgrounds perform less well in disciplinary achievements than their counterparts, learning intercultural knowledge via a CLIL approach can help motivate most participants and help them build a positive attitude. In short, the coursebook users perceived that CLIL does indeed have the potential for the development of intercultural attitudes and the vital cultivation of critical cultural awareness (Méndez García, 2012).

Table $5 \mathrm{t}$ test by gender (Female vs. Male)

\begin{tabular}{|c|c|}
\hline 1. The social and cultural contexts in the textbook are understandable. & $t=.775 *$ \\
\hline $\begin{array}{l}\text { 2. The content of the textbook is free from stereotypical images and } \\
\text { information. }\end{array}$ & $t=-.385 * *$ \\
\hline $\begin{array}{l}\text { 4. The cultural content of the textbook increases sensitivity to cultural } \\
\text { diversity }\end{array}$ & $t=1.055^{*}$ \\
\hline $\begin{array}{l}\text { 6. The cultural content of the textbook does not assign values to cultural } \\
\text { differences. }\end{array}$ & $t=.260 * *$ \\
\hline
\end{tabular}

Table $6 \mathrm{t}$ test by location of internship (Domestic vs. Overseas)

\begin{tabular}{|ll|c|}
\hline 5. & $\begin{array}{l}\text { The cultural content of the textbook increases sensitivity to cultural } \\
\text { diversity }\end{array}$ & $t=.351 *$ \\
\hline 9. & $\begin{array}{l}\text { The book expresses positive views of ethnic origins, occupations, age } \\
\text { groups, social groups and disability. }\end{array}$ & $\boldsymbol{t}=-.619 * *$ \\
\hline 11. & Cultural content is usually presented with a validating context. & $\boldsymbol{t}=-.781^{*}$ \\
\hline
\end{tabular}


Table 7 ANOVA-test by English proficiency

\begin{tabular}{|c|c|}
\hline \begin{tabular}{|l}
8. \\
$\begin{array}{l}\text { The textbooks represent cultural content without } \\
\text { stereotypes or an essentialist perspective. }\end{array}$
\end{tabular} & $(F(3: 28)=3.042, p<.05$ \\
\hline 10. The cultural information is relevant and interesting. & $(\boldsymbol{F}(3: 2$ \\
\hline
\end{tabular}

\subsection{Differences in the CQ performance of course-takers and non-course-takers}

Although the coursebook was reported to be effective for its CLIL users, to what extent the CLIL and non-CLIL groups' intercultural knowledge or understanding has maintained or changed precisely before and after the explicit instruction can only be understood by administering actual measurements of their CQ performance as pre- and post-tests. Table 8 tabulates the results of their overall CQ performance of the two groups before and after the teaching. On average, both groups can be categorised as intermediate to high CQ performers, no matter whether before or after the course, with a mean over 5.0 out of 7.0. However, in the pre-test, the non-CLIL group self-rated their CQ scores higher than the CLIL group did, as was the case in the post-test. Furthermore, a $t$ test revealed that the CLIL group made highly significant progress in CQ performance after the explicit instruction, whereas the non-CLIL group showed a significant decline in CQ performance after one semester without the instruction. It is presumed that those who had not taken the course became anxious and naturally rated the CQ scale items lower when they had to start an internship without provision for adaptation. Although the increase and the drop seem reasonable, the results clearly exhibit the effectiveness of teaching cultural knowledge explicitly and the loss of intercultural competence without external support. Traditionally, there has been a lack of good practice and insufficient attention to intercultural dimensions in English language teaching and teacher preparation. However, our study provides evidence that a language-based CLIL course can be useful, and the integration of language and intercultural understanding provides a renewed basis for good practice of developing learners' intercultural competence (Byram, Nichols, \& Stevens, 2001). In addition, the results confirm what we found when evaluating the coursebook, namely that CQ can successfully predict the commitment to and satisfaction with the course (Ramsey \& Lorenz, 2016).

Table 8 Pre- and post-test CQ scales for CLIL and non-CLIL learners

\begin{tabular}{|l|l|l|l|}
\hline & Pre-test & Post-test & t-test \\
\hline CLIL learners & 5.053053053 & 5.495495495 & $\mathrm{t}=-17.806^{* * *}$ \\
\hline Non-CLIL learners & 5.767567568 & 5.570945946 & $\mathrm{t}=2.442 *$ \\
\hline
\end{tabular}

Tables 9 to 11 display the significant differences in CQ performance before and after the instruction by the two variables, gender and internship location and after the instruction by the nationality variable, respectively. Firstly, before the explicit instruction, female learners showed significantly higher CQ scores for many items than male learners did; yet, the differences between genders decreased to only three items after the instruction (see Table 9). Although females generally reveal better foreign language learning outcomes than males do (Farashaiyan \& Hua, 2012), in a language-based culture course, male and female groups separately show significantly higher CQ scales in certain items. For instance, before the course the male CLIL learners tended to be more aware of cultural cues during interactions, testifying their assumptions of cultural knowledge; on the contrary, the 
female students were inclined to rely on "appropriate verbal and nonverbal behavior when interacting with people from different cultures" (Bucker et al., 2015). However, after the pedagogical intervention, not only the statistical diversities between males and females reduced but the CQ indicators also changed. With the explicit instruction, female students seemed better able to acquire more knowledge about cultural norms, conventions and practices than male learners. The CLIL course is arguably able to increase the two groups' intercultural competence and reduce the difference between them.

Table $9 \mathrm{t}$ test before/after the instruction by gender

\begin{tabular}{|c|c|}
\hline Before instruction & t test \\
\hline I can speak and understand many languages. (MO) & $\mathrm{t}=-1.278^{*}$ \\
\hline $\begin{array}{l}\text { I think about possible cultural differences before meeting people from other } \\
\text { cultures. (MC) }\end{array}$ & $\mathrm{t}=-.138 * *$ \\
\hline $\begin{array}{l}\text { I am conscious of how other people's culture influences their thoughts, feelings, } \\
\text { and actions. (MC) }\end{array}$ & $\mathrm{t}=.451 * *$ \\
\hline $\begin{array}{l}\text { I double check the accuracy of my cultural knowledge during intercultural } \\
\text { interactions. (MC) }\end{array}$ & $\mathrm{t}=-.153^{*}$ \\
\hline I change my use of pause and silence to suit different cultural situations. (BH) & $\mathrm{t}=-.153 *$ \\
\hline $\begin{array}{l}\text { I vary my verbal behaviors (accept, tone, rate of speaking) to fit specific cultural } \\
\text { contexts. }(\mathrm{BH})\end{array}$ & $\mathrm{t}=.176 * *$ \\
\hline $\begin{array}{l}\text { I change my nonverbal behaviors (hand gestures, head movements) to fit the } \\
\text { cultural situation. }(\mathrm{BH})\end{array}$ & $\mathrm{t}=.503^{*}$ \\
\hline \multicolumn{2}{|l|}{ After instruction } \\
\hline $\begin{array}{l}\text { I can describe differences in kinship systems and role expectations for men and } \\
\text { women across cultures. (CO) }\end{array}$ & $\mathrm{t}=1.300^{*}$ \\
\hline $\begin{array}{l}\text { I can describe different views of beauty and aesthetics across cultural settings. } \\
\text { (CO) }\end{array}$ & $\mathrm{t}=.792 * *$ \\
\hline $\begin{array}{l}\text { I change my nonverbal behaviors (hand gestures, head movements) to fit the } \\
\text { cultural situation. }(\mathrm{BH})\end{array}$ & $\mathrm{t}=1.281 *$ \\
\hline
\end{tabular}

Differing from the previous variable, gender, the factor of internship location led to more significant differences by the end of the instruction (week 18) when compared to week 1 . Those who chose overseas internship showed significantly stronger motivational and behavioural CQ scales than those who planned to stay in their home country before the course. Nevertheless, after the 18-week course instruction, except for the indicator, i.e. I double check the accuracy of my cultural knowledge during intercultural interactions, the former group exhibited significantly higher CQ scores than the latter group for many items, in particular for the performance of motivational and behavioural CQ. This implies that the course not only fortifies their motivation and confidence for going overseas for internship but also enables them to demonstrate appropriate (non)verbal behaviours while interacting with people from other cultural backgrounds. Besides, they are also more willing to update their previously-mistaken knowledge about cultures; this strategy can greatly help them to habituate themselves well to live, work or study in foreign contexts. 
Table $10 \mathrm{t}$ test before/after the instruction by internship location

\begin{tabular}{|l|l|}
\hline Before instruction & $t$ test \\
\hline I truly enjoy interacting with people from different cultures. (MO) & $\mathrm{t}=-1.308^{*}$ \\
\hline $\begin{array}{l}\text { I vary the way I show gratitude (express appreciation, accept compliments) based } \\
\text { on the cultural context. (BH) }\end{array}$ & $\mathrm{t}=-.556^{*}$ \\
\hline After instruction & \\
\hline $\begin{array}{l}\text { I truly enjoy interacting with people from different cultures. (MO) } \\
\text { (MO) }\end{array}$ & $\mathrm{t}=-.470^{*}$ \\
\hline $\begin{array}{l}\text { I double check the accuracy of my cultural knowledge during intercultural } \\
\text { interactions. (MC) }\end{array}$ & $\mathrm{t}=-.513^{* *}$ \\
\hline $\begin{array}{l}\text { I update my cultural knowledge after a cultural misunderstanding. (MC) } \\
\text { I change my use of pause and silence to suit different cultural situations. (BH) }\end{array}$ & $\mathrm{t}=-.325^{* * *}=-.885^{*}$ \\
\hline $\begin{array}{l}\text { I vary my verbal behaviors (accept, tone, rate of speaking) to fit specific cultural } \\
\text { contexts. (BH) }\end{array}$ & $\mathrm{t}=-.717^{*}$ \\
\hline $\begin{array}{l}\text { I change how I make requests of others depending on their cultural background. } \\
\text { (BH) }\end{array}$ & $\mathrm{t}=-.145^{* *}$ \\
\hline
\end{tabular}

Finally, Table 11 reveals the significant differences in the CQ scales of local and international students. Interestingly, except for the indicator, I change my nonverbal behaviors (hand gestures, head movements) to fit the cultural situation where the home students rated higher scores, the international students showed significantly higher CQ performance than the local learners for many items, but we have to acknowledged the uneven student numbers between the two groups (local: 31 ; international: 2). As one aim of using CQS was to assess if students are qualified to join overseas exchange or study abroad programmes, the current international students may have been equipped with an appropriate mindset of cultural adaptation and orientation in different contexts, although it is unclear if they had received any CQ training before coming to Taiwan. However, they are successfully surviving in the researched setting, indicating that their CQ scale should be relatively high.

Significant differences between the home and the international students can be found across the four dimensions of intercultural competence. The present international students were mixed with the local students in classes, in dormitories and in extracurricular activities, which not only facilitates intercultural interactions but also promotes intrinsic motivation and self-determined extrinsic motivation (Holtbrügge \& Engelhard, 2016). This drive interests them in understanding the local cultures which they are currently exposed to, in taking action to be aware of and to check cultural differences and then changing their behaviours and employing skills during multicultural encounters. Our finding also indicates that obtaining an undergraduate degree from a foreign country can help increase individual CQ performance (Ahn \& Ettner, 2013). Thus, it is also predicted that the local students' CQ will be increased as well after the one-year overseas experience of working, studying and living abroad. 
Table $11 \mathrm{t}$ test before/after the instruction by nationality

\begin{tabular}{|l|l|}
\hline After instruction & $t$-test \\
\hline $\begin{array}{l}\text { Given a choice, I prefer work groups composed of people with different } \\
\text { (rather than similar) cultural backgrounds. (MO) }\end{array}$ & $\mathrm{t}=-1.854^{*}$ \\
\hline $\begin{array}{l}\text { I value the reputation I would gain from developing global networks and } \\
\text { connections. (MO) }\end{array}$ & $\mathrm{t}=-2.024^{*}$ \\
\hline $\begin{array}{l}\text { I can describe the different cultural value frameworks that explain behaviors } \\
\text { around the world. (CO) }\end{array}$ & $\mathrm{t}=-2.430^{*}$ \\
\hline $\begin{array}{l}\text { I can describe differences in kinship systems and role expectations for men } \\
\text { and women across cultures. (CO) }\end{array}$ & $\mathrm{t}=-2.610^{*}$ \\
\hline $\begin{array}{l}\text { I adjust my understanding of a culture while I interact with people from that } \\
\text { culture. (MC) }\end{array}$ & $\mathrm{t}=-2.034^{*}$ \\
\hline $\begin{array}{l}\text { I double check the accuracy of my cultural knowledge during intercultural } \\
\text { interactions. (MC) }\end{array}$ & $\mathrm{t}=-2.541^{*}$ \\
\hline $\begin{array}{l}\text { I update my cultural knowledge after a cultural misunderstanding. (MC) } \\
\text { cultural contexts. (BH) }\end{array}$ & $\mathrm{t}=-2.024^{*}$ \\
\hline $\begin{array}{l}\text { I change my nonverbal behaviors (hand gestures, head movements) to fit the } \\
\text { cultural situation. (BH) }\end{array}$ & $\mathrm{t}=.259^{*}$ \\
\hline I modify the way I disagree with others to fit the cultural setting. (BH) & $\mathrm{t}=-.024^{*}$ \\
\hline
\end{tabular}

\subsection{Interviews with the material writers and CLIL learners}

To verify the data collected in the surveys and to obtain deeper understanding of the values of producing a CLIL culture coursebook, interviews with the book users and writers were administered. Several themes were generated as follows.

Intercultural competence increased: All the student interviewees reported that they perceived an increase in their intercultural competence after the course. The course helped combine their piecemeal intercultural knowledge into a complete concept. Those who planned to go overseas for an internship highly recommended the benefits of joining the course and using the book. For all of them, staying in a foreign country for one year was their first such experience and the course brought them confidence in their ability to survive abroad and strengthened their belief that they had made the correct decision to go overseas. One male student commented that "I'm going to have my internship in Singapore where many different ethnic groups have their own cultures. The course made me more open-minded to accept others." Those who planned to stay in Taiwan also responded that "Many tourists from different countries visit Taipei every year and if I have more intercultural knowledge I can clearly know how to interact with them, to serve them and not to offend them as a hotel front desk clerk."

No adequate assessments of culture knowledge: However, when they were asked if assessing intercultural competence was essential, such as via examinations, and how to assess it, both the book users and writers expressed a similar attitude. The learners did not believe having them take formal paper-and-pencil examinations was necessary or effective as they argued that culture is a representation of a norm and to avoid stereotyping other cultures, judging it as either right or wrong is unsuitable. The book authors also remarked that instead of formal examinations, having the learners do research and present it seems 
more useful and interesting, which offers them a chance to look for more possibilities of a conventionally-defined culture.

Requiring learner-centred teaching activities: Regarding how to deliver the course, teacher and student interviewees had divided opinions. The students liked the idea of the teacher using 'Padlet' (a tool to allow learners to contribute to and read documents on-line) to have them contribute and share ideas, but also insisted that teaching activities should be more learner-centred, offering them opportunities to interact with peers in class. They suggested that teachers have students perform dramas, make oral presentations, and have pop quizzes to deliver cultural knowledge instead of having teacher-dominant lectures. One female learner said, "Students like acting and the drama performance not only motivates us but makes knowledge easy to remember." However, one male teacher commented that he would use his experiences as examples to teach the course and one female teacher also expressed that students still need the teacher's guidance as foreign cultures may be new to them.

Native speakers of English as better instructors: When asked if native speakers or non-native speakers of English teachers were more eligible as course instructors, the responses varied between the student and teacher interviewees too. Interestingly, the learners did not show a preference for teacher's mother tongues or nationalities; "I think teachers are ready and capable of teaching the course if s/he is assigned the course, no matter whether s/he is an English speaker or not", one student said. In contrast, the book writers showed contrasting attitudes. NS teachers argued that they were comparatively more qualified to teach the course since they have profound experiences of intercultural encounters, but NNS teachers also believed that they were capable of teaching the course because they obtained postgraduate degrees in English-speaking countries and knew the cultural differences between western and eastern societies well.

Better English competence for interaction: One of the targets of the course is to reinforce learners' English ability, and all the students agreed that they had experienced an increase in their ability by the end of the course. They expressed that they would be more comfortable and confident while interacting with people from different cultural backgrounds by using English. For instance, one male student who was planning to go to the United Kingdom for his internship commented on one unit, Sports, saying "Now I know I can talk about curling with Brits. This is a new word I learnt and a new sport I know which can be a good ice-breaker with British people. In Taiwan, we nearly know nothing about it but now I know its rules and can describe them in English."

More learning resources and teaching support required: Since this was the first trial to produce a contextualised culture coursebook and implement it using the CLIL approach, some opinions requesting future amendments were raised. The student group asked for the integration of more technological devices such as mobile phones into the learning activities; in other words, the coursebook lacks ICT design which may demotivate the mobile-generation students. Similarly, the book authors also admitted that owing to their backgrounds, i.e. applied linguists or English teachers, the book was designed in a less technologically interesting way and more supports for future teachers were also needed. For instance, a teacher manual should be written in case the NNS instructors may need some cultural notes while teaching. One female teacher remarked that "Not every NNS teacher is well equipped with intercultural competence so it may be demanding for him/her to teach the course if no extra supplementary materials are provided."

To conclude this section, nearly all the interviewees agreed with the importance of raising learners' cultural awareness and preparing their intercultural competence in such a 
globalised society, in particular, if they were planning to travel overseas for a one-year internship. The interviewees agreed that the production is highly satisfactory. The users' CQ also significantly increased and their English proficiency improved too, which indicates that we successfully achieved the purposes of the course design and the CLIL implementation.

\section{CONCLUSION}

The research investigated the university students' evaluation of a self-produced language-based culture CLIL coursebook and measured the change in their CQ performance after an 18-week instruction. Two questionnaire surveys and the focus-group interviews were administered. The results reveal that the users were highly satisfied with the self-designed coursebook in terms of learning intercultural knowledge explicitly. In addition, the students also experienced a significant increase in CQ after the course instruction. The variables of gender, internship location, English proficiency and nationality also caused some statistical differences among the groups. The interviews with the learners and book writers confirmed the effects of the coursebook accommodating the dual focuses of a CLIL approach, that is, addressing both language proficiency and content knowledge. However, some concerns such as assessment, teaching activities and external supports were also raised for future amendments and implementations.

The research has the following pedagogical implications. First, it is suggested that a culture coursebook should be written not only with an international team but it should also be reviewed by international scholars or users, in particular by those from non-Anglophone cultures. Although English is often the target language in most CLIL contexts in the world, culture competence developed under the CLIL approach should not be represented by English or Anglophone cultures only. Nowadays English is regarded as world Englishes, a lingua franca (ELF) or an international language (EIL). Content and interaction are centred in classrooms where varieties of English could be taught and learnt and all of these varieties, no matter whether they are localised or standardised English, developed with their specific features or cultures, should receive equal status, respect and treatment in a CLIL classroom (McKay, 2018). This principle is also applied to CLIL material writers and publishers. Cross-cultural knowledge in CLIL education should not be narrowly defined according to geographical boundaries; instead, any association with small or large cultures (see Holliday, 1999) in CLIL materials and class practices should be equally emphasised and represented.

Second, the present research evidences that cultural competence can be effectively enhanced through explicit instruction. Not many CLIL studies in the literature clearly or specifically address how and to what extent cultural awareness has been developed in CLIL education; rather, hidden cultural notes together with appropriate (non)linguistic strategies are often expected to be realised implicitly and naturally (Meyer, 2010). However, the CLIL approach has been utilised in EFL (English as a Foreign Language) or language-based CLIL classrooms to teach learners cross-cultural awareness, and this has been proved to be effective (Diab, Abdel-Haq, \& Aly, 2018). In contrast, in content-oriented CLIL courses, measuring cross-cultural competence is still under-represented and it is suggested that cultural notes should be highlighted and intercultural knowledge should also be explicitly taught either in a stand-alone course or an integrated model when applying the CLIL approach. 
Since this research might be one of the first few attempts to evaluate a tailor-made CLIL culture coursebook and to examine its learners' CQ scale before and after using it, several future studies can be carried out to complement it. First, evaluating a course without considering its instructor's performance cannot be considered completely holistic. It is suggested that researchers can observe and compare how NS and NNS teachers may conduct their instructions differently and how it affects learners' development of their CQ competence. Second, as the sample size in the present study is not large, in particular the number of international students, it raises concerns about the validity of the research; thus, it is recommended that future implementations invite more international students and local participants with different majors to join the research to attain a higher representativeness.

Note: ${ }^{1}$ In this survey, choices of 4 and 5 in the 5-pont Likert scale are classed as high agreement, 3 as neutral, and 1 and 2 are treated as disagreement.

Acknowledgements. This research was co-sponsored by the Ministry of Science and Technology (MOST 107-2410-H-328 -003 -) and Higher Education Sprout Project, Ministry of Education, Taiwan. In addition, the researcher would also like to offer his gratitude to the colleagues who collaboratively completed the coursebook used for this study.

\section{REFERENCES}

Ahn, M. J., \& Ettner, L. (2013). Cultural intelligence (CQ) in MBA curricula. Multicultural Education \& Technology Journal, 7(1), 4-16.

Baecher, L., Farnsworth, T., \& Ediger, A. (2014). The challenges of planning language objectives in. content-based ESL instruction. Language Teaching Research, 18(1), 118-136.

Ball, P., Kelly, K., \& Clegg, J. (2015). Putting CLIL into practice. Oxford, UK: Oxford University Press.

Banegas, D. L. (2014). An investigation into CLIL-related sections of EFL coursebooks: Issues of CLIL inclusion in the publishing market. International Journal of Bilingual Education and Bilingualism, 17(3), 345-359.

Banegas, D. L. (2015). Sharing views of CLIL lesson planning in language teacher education. Latin American Journal of Content \& Language Integrated Learning, 8(2), 104-130.

Bell, J., \& Gower, R. (2011). Writing course materials for the world: A great compromise. In B. Tomlinson (Ed.), Materials development in language teaching (pp. 135-150). Cambridge, UK: Cambridge University Press.

Bücker, J. J., \& Korzilius, H. (2015). Developing cultural intelligence: assessing the effect of the Ecotonos cultural simulation game for international business students. The International Journal of Human Resource Management, 26(15), 1995-2014.

Bücker, J., Furrer, O., \& Lin, Y. (2015). Measuring cultural intelligence (CQ) A new test of the CQ scale. International Journal of Cross Cultural Management, 15(3), 259-284.

Buchtel, E. E. (2014). Cultural sensitivity or cultural stereotyping? Positive and negative effects of a cultural psychology class. International Journal of Intercultural Relations, 39, 40-52.

Byram, M., Nichols, A., \& Stevens, D. (Eds.). (2001). Developing intercultural competence in practice (Vol. 1). Exeter, UK: Multilingual Matters. 
CIC (Cultural Intelligence Centre). (2019). Culture. Retrieved on 5 October, 2019 from. https://culturalq.com/about-cultural-intelligence/culture/

Chao, M. M., Takeuchi, R., \& Farh, J. L. (2017). Enhancing cultural intelligence: The roles of implicit culture beliefs and adjustment. Personnel Psychology, 70(1), 257-292.

Coyle, D. (1999) Theory and planning for effective classrooms: Supporting students in content and language integrated learning contexts. In J. Masih (Ed.), Learning through a foreign language (pp.46-62). London: CILT.

Coyle, D. (2007). Content and language integrated learning: Towards a connected research agenda for CLIL pedagogies. International Journal of Bilingual Education and Bilingualism, 10(5), 543-562.

Coyle, D. (2008). CLIL-A pedagogical approach from the European perspective. Encyclopedia of Language and Education, 1200-1214.

Coyle, D., Hood, P., \& Marsh, D. (2010). CLIL: Content and language integrated learning. Cambridge, UK: Cambridge University Press.

Cummins, J. (2004) Using IT to create a zone of proximal development for academic language learning: A critical perspective on trends and possibilities. In C. Davison (Ed.), Information Technology and Innovation in Language Education (pp. 105-126). Hong Kong: Hong Kong University Press.

Diab, A. A. M., Abdel-Haq, E. M., \& Aly, M. A. S. (2018). The Effectiveness of Using Content and Language Integrated Learning (CLIL) Approach to enhance EFL student teachers' cultural awareness. Online Submission. 1-27. Retrieved on 3 October, 2019 from https://files.eric.ed.gov/fulltext/ED582276.pdf

Douglas Brown, H. (1980) Principles of Language Learning and Teaching. New Jersey: Prentice Hall-Englewood Cliffs.

Earley, P. C., \& Peterson, R. S. (2004). The elusive cultural chameleon: Cultural intelligence as a new approach to intercultural training for the global manager. Academy of Management Learning \& Education, 3(1), 100-115.

Eisenberg, J., Lee, H. J., Brück, F., Brenner, B., Claes, M. T., Mironski, J., \& Bell, R. (2013). Can business schools make students culturally competent? Effects of cross-cultural management courses on cultural intelligence. Academy of Management Learning \& Education, 12(4), 603-621.

Engle, R. L., \& Crowne, K. A. (2014). The impact of international experience on cultural intelligence: An application of contact theory in a structured short-term programme. Human Resource Development International, 17(1), 30-46.

Erez, M., Lisak, A., Harush, R., Glikson, E., Nouri, R., \& Shokef, E. (2013). Going global: Developing. management students' cultural intelligence and global identity in culturally diverse virtual teams. Academy of Management Learning \& Education, 12(3), 330-355.

Farashaiyan, A., \& Hua, T. K. (2012). On the relationship between pragmatic knowledge and language proficiency among Iranian male and female undergraduate EFL learners. 3L: Language, Linguistics, Literature, 18(1), 33-46.

Farzaneh, N., Kohandani, M., \& Nejadansari, D. (2014). A textbook evaluation of socio-cultural contexts in top notch series. Procedia-Social and Behavioral Sciences, 98, 472-481.

Fenton, A. (2004). Weft QDA. Retrieved from http://www.pressure.to/qda/ on 8 August, 2019.

Fernández-Sanjurjo, J., Fernández-Costales, A., \& Arias Blanco, J. M. (2019). Analysing students' content-learning in science in CLIL vs. non-CLIL programmes: Empirical evidence from Spain. International Journal of Bilingual Education and Bilingualism, 22(6), 661-674. 
Fischer, R. (2011). Cross-cultural training effects on cultural essentialism beliefs and cultural intelligence. International Journal of Intercultural Relations, 35(6), 767-775.

Floimayr, T. (2010). CLIL in Biology: An evaluation of existing teaching materials for Austrian schools. VIEWS: Vienna English Working Papers, 19(3), 21-28. Retrieved from https://anglistik.univie.ac.at/fileadmin/user_upload/i_anglistik/Department/Views/Uploads /Views_0703_specissue.pdf

Holliday, A. (1999). Small cultures. Applied linguistics, 20(2), 237-264.

Holtbrügge, D., \& Engelhard, F. (2016). Study abroad programs: Individual motivations, cultural intelligence, and the mediating role of cultural boundary spanning. Academy of Management Learning \& Education, 15(3), 435-455.

Logioio, A. J. (2010). Raising intercultural awareness at primary level through storytelling within a CLIL approach. Unpublished doctoral dissertation, Faculdade de Ciências Sociais e Humanas, Universidade Nova de Lisboa.

McKay, S. L. (2018). English as an International language: What it is and what it means for pedagogy. RELC Journal, 49(1), 9-23.

Mehisto, P. (2012). Criteria for producing CLIL learning material. Encuentro, 21, 15-33. Retrieved on 5 May, 2019 from http://files.eric.ed.gov/fulltext/ED539729.pdf

Méndez García, M. D. C. (2012). The potential of CLIL for intercultural development: A case study of Andalusian bilingual schools. Language and Intercultural Communication, 12(3), 196-213.

Meyer, O. (2010). Towards quality CLIL: Successful planning and teaching strategies. PULSO, Revista de Educación, 33, 11-29.

Nikula, T. (2012). On the role of peer discussions in the learning of subject-specific language use in CLIL. In E. Soler, \& M. Safont-Jordà (Eds.), Discourse and language learning across L2 instructional settings (pp. 133-153). Amsterdam, The Netherlands: Rodopi.

Oprescu, M. (2015). Cultural identity through CLIL. Romanian Journal of English Studies, 12(1), 34-39.

Papadopoulos, I., \& Griva, E. (2014). Learning in the traces of Greek Culture»: a CLIL project for raising cultural awareness and developing L2 skills. International Journal of Learning, Teaching and Educational Research, 8(1), 76-92.

Ramsey, J. R., \& Lorenz, M. P. (2016). Exploring the impact of cross-cultural management education on cultural intelligence, student satisfaction, and commitment. Academy of Management Learning \& Education, 15(1), 79-99.

Rodríguez, L. M. G., \& Puyal, M. B. (2012). Promoting intercultural competence through literature. in CLIL contexts. Atlantis, 34(2), 105-124.

Sanjurjo, J. F., Blanco, J. M. A., \& Fernández-Costales, A. (2018). Assessing the influence of socio-economic status on students' performance in Content and Language Integrated Learning. System, 73, 16-26.

Sherwood, J. (2019). What is cultural competence? Retrieved on 5 October, 2019 from https://sydney.edu.au/nccc/about-us/what-is-cultural-competence.html

Sudhoff, J. (2010). CLIL and intercultural communicative competence: Foundations and approaches towards a fusion. International CLIL Research Journal, 1(3), 30-37.

Tomlinson, B. (2012). Materials development for language learning and teaching. Language Teaching, 45(2), 143-179.

Varela, O. E., \& Gatlin-Watts, R. (2014). The development of the global manager: An empirical study on the role of academic international sojourns. Academy of Management Learning \& Education, 13(2), 187-207. 
Yang, W. H. (2015). Content and language integrated learning next in Asia: Evidence of learners' achievement in CLIL education from a Taiwan tertiary degree programme. International Journal of Bilingual Education and Bilingualism, 18(4), 361-382.

Yang, W. H. (2018). Evaluating contextualized content and language integrated learning materials at tertiary level. Latin American Journal of Content \& Language Integrated Learning, 11(2), 236-274.

Yang, W. H. (2020). Toward a bilingual Taiwan: How can CLIL help? The Journal of Japan CLIL Pedagogy Association, 2, XX-XX. (An invited paper under review). 